edge Initiative accomplished in a timely fashion. Once done, Drew could claim credit for a full innovation, not an innovation that was two-thirds complete. Their sense of urgency invigorated the other trustees, and the full Board acted in December 1988 to authorize additional funding.

With funding assured, the library began negotiating with a small group of library-automation vendors who could work in the Drew network environment and promise delivery of a system by September 1989. We were searching for a partnership similar to those we had developed with Digital, Bell Atlanticom, Intecom, Octel, and MCI during the installation of the voice-data system. Any new system must add value to the present system and for the library, that meant adding Boolean searching and the potential for other machine-readable databases in the future.

In June 1989 we signed a contract with Data Research Associates, and installed the system over the summer. By the fall, Drew University had a complete network with an online public access catalog that featured Boolean access for all users, along with electronic mail, an online encyclopedia, and many other features. Six years after the introduction of the Computer Initiative, Drew has a system that can serve as a model for other liberal arts institutions in its comprehensiveness, simplicity, and simultaneous concern for cost-containment and innovation.

Those institutions still searching for ways to fund automating a library, or wiring a campus, or delivering sufficient personal computing power to students may want to consider Drew's approach. While the library went without funding in the years when it sought funding for library automation as an isolated activity, the proponents of the network needed the punch of what a fully integrated library system would add to the network in information delivery to sell the network to some faculty and trustees. Coupling the vision with sound budgeting and the need to replace an outdated telephone system was vital. Both the library and the office of the vice-president for technology and planning found that the strongest case for the Knowledge Network rested in its relation not to a given computer or piece of software, but to the vision of value-added information services and delivery.

\title{
NOTIS instruction for the public: Current tools and future needs
}

\author{
By Lynn Westbrook
}

\author{
Coordinator for Reference and Instruction \\ Undergraduate Library, University of Michigan
}

Joining more than 100 other libraries across the country, the University of Michigan recently developed a local version of the NOTIS online catalog. This created a critical need for basic training materials for the public. As part of a User Education Committee Subcommittee on Training for the Public, five librarians created an extensive set of lectures, transparencies, handouts, and exercises that were then distributed to each of the 21 system libraries campuswide. These materials, available on request from LOEX, ${ }^{1}$ are based on a combination of the practical demands faced by busy librarians and basic pedagogical principles. Some portion

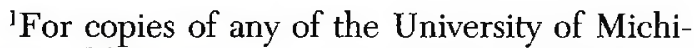
gan's public training material, write to the following address: LOEX, Eastern Michigan University, Ypsilanti MI 48197; (313) 487-0168. of the materials should help meet almost any need with the NOTIS system, or even similar systems.

From a very practical viewpoint, the librarians would be teaching under a wide variety of circumstances. Some would have access to microcomputer centers with a separate workstation for every student, while others would have only an overhead projector in a seminar room. Some would have faculty eager for a full fifty-minute session, while others would be teaching undergraduates at brief walk-in sessions. Many would find reference and even circulation staff expected to brief patrons quickly, while BI librarians would be asked to add a few words onto the end of an already crowded presentation. A few would have access to lab time, but most would not. These widely divergent needs meant that everything must be prepared for fifty-, twenty-, and ten-minute presentations. Each of these presentations had to be prepared both with 
and without the use of workstations.

The subcommittee had to deal with teaching the same fundamental material to widely divergent adult audiences with various learning styles. Everyone-faculty, graduate students, undergraduates, university staff, temporary library staff, the computer illiterate and the power user-would need to be reached as effectively as possible. As Betsy Baker has noted, the nature of a database is in itself a valid and potentially useful conceptual framework. ${ }^{2}$ Except for the concept of the database, the basic material is essentially mechanical; the NOTIS prompts and help screens make it rather straightforward for many. The subcommittee was concerned with the oft-stated need to make use of the opportunity to teach so fundamental a library tool as the catalog. ${ }^{3}$ With care, a few of the more common misconceptions about catalogs, both paper and electronic, might be mitigated. For example, the importance of controlled vocabulary versus natural language and the complexities of corporate author searches might be broached when appropriate. This combination of learning styles and material required that lectures, discussion sessions, and learning cycles be created with due attention paid to the needs of the visual learner.

Of course, once the keyword/boolean feature was added to the University of Michigan system, an entirely new piece of material was required. Since this feature was added well after the User Education Committee had been disbanded, the material on it was created at a later date. It too is available from LOEX.

These practical and educational considerations eventually required the creation of ten separate teaching scripts, each of which had a separate set of transparencies (the keyword/boolean material was added later). The entire set, including transparency masters, was organized so that individuals could have all or any portion of it. Many libraries keep the entire set in a ring binder so that staff can pull out a custom-made packet of material for most situations. Although the example searches were always open to alteration, an effort had been made to include something from most disciplines.

The fifty-minute script is available as a lecture, discussion (with workbook), and learning cycle. All three are available in two forms: for use with work-

${ }^{2}$ Betsy Baker, "A Conceptual Framework for Teaching Online Catalog Use," Journal of Academic Librarianship 12 (May 1986): 90-96.

${ }^{3}$ For further reading in this area, see Popa Opritsa and Deborah Metzger, "Teaching Search Techniques on the Computerized Catalog and on the Traditional Card Catalog: A Comparative Study," College and Research Libraries 49 (May 1988): 263-74. stations and for use without workstations. Minor editing made the two forms relatively easy to set up. In addition to covering the contents of the database, these scripts include title searching with examples of index and guide screens, four types of author searching, and all the complexities of subject searching. Whenever possible the students actually run each type of search. Common problems are demonstrated such as using initial articles in title searching, corporate author hierarchy, and the four types of subject subdivision (time, location, topic, and format).

The twenty-and ten-minute scripts only worked in the lecture mode although they too were set up in both forms, with and without workstations. The twenty-minute scripts dropped quite a bit of detail involving common problems, did only one author search, and spent most of the subject search time on moving around the resulting screens. The tenminute scripts concentrate on the content of the database, mention the three types of searches, and illustrate moving around in the results of a title search. Both scripts emphasize seeking reference assistance for any unsatisfactory search.

Once the material had been created it was printed, sorted, made available on IBM and Macintosh diskettes, and distributed. For those who did not want to receive their material in the mail, two sessions were held at which staff could come to pick up their material and receive further explanations of the options available. An electronic discussion forum was set up in which ideas, comments, and feedback were exchanged. Ten months after the initial material was distributed, a brief typed list of changes (required by the growing database), a transparency master based on the new edition of Library of Congress Subject Headings (LCSH), updated exercises, and the new script for keyword/ boolean work were distributed. Corrections were then made on the original disks and an opportunity provided for anyone to receive the revisions.

With less than a year of experience with the material, a few points have come to the fore. $\mathrm{Li}$ brarians did indeed need all of the scripts; graduate students and faculty required the fifty-minute sessions almost exclusively; and the undergraduates relied on the twenty-minute sessions. The tenminute sessions were used by individuals in ad hoc one-to-one efforts. In the fall term, several libraries set up and publicized, through ads in the student newspaper and flyers, a coordinated roster of training sessions of various types. This successful coordination allowed library users to attend whatever session was most convenient for them, no matter which library gave it. The opportunity to use the learning cycle set has not yet arisen. Having everything on disk has allowed not only libraries but even individuals within specific libraries to customize their scripts. The electronic network was most 
effective during its first few months and served as an excellent source of example searches and teaching tips.

Future developments are already affecting current practice. As patrons begin to access the system at remote sites, without the ready aid of any library staff or even a copy of LCSH, minimal training becomes even more important. For example, while using keyword searching to bypass LCSH is sometimes successful, it also leads people to erroneous conclusions that a little information could correct. Others assume that the system is a complete listing of all holdings, despite the introductory screen. While BI is not going to solve all of these ills, for the first time the library is physically moving away from its staff into dorms, private homes, and the more than thirty microcomputer sites all over campus. Paperchase's UM-Medline is already providing online access to Index Medicus using the same readily available software so that some patrons use a single workstation to search for both books and articles on medical topics. Discussions are underway about mounting the Wilson tapes onto the same system. This requires strong outreach and support efforts from libraries to continue providing service where patrons need it. Relying on access to students via the usual faculty conduits may not meet this new need. As well attended, walk-in training sessions demonstrated, patrons will choose to learn when given a convenient, relevant opportunity. Another challenge of this new BI effort is to use the hook of teaching online catalog mechanics to delve into critical thinking and problem solving, where possible. ${ }^{4}$ Patrons will then learn to question less than optimal results of their searches, no matter where those searches takes place. The challenge is exciting and will only continue to grow.

${ }^{4}$ For further reading on critical thinking, see Eugene Engeldinger, "Bibliographic Instruction and Critical Thinking: The Contribution of the Annotated Bibliography," RQ 28 (Winter 1988): 195-202; and Joan Bechtel, "Developing and Using the Online Catalog to Teach Critical Thinking," Information Technology and Libraries 7 (March 1988): $30-40$.

\section{ACRL candidates, 1990 elections}

\section{Who's who on the Spring ballot.}

$\mathbf{T}$ he listing for each of the following candidates includes their title, institution, and institutional address.

\section{Vice-President/President-Elect}

Anne K. Beaubien, Head, Cooperative Access Services, 106 Hatcher Graduate Library, University of Michigan, Ann Arbor, MI 48109-1205; Maxine H. Reneker, Director of Instructional and Research Services, Stanford University Libraries, Stanford, CA 94305-6004.

\section{Board of Directors}

Division Councilor: Linda Piele, Associate
Director for Public Services, Library/Learning Center, University of Wisconsin-Parkside, Kenosha, WI 53141; Rochelle Sager, Associate Dean of Libraries, Adelphi University, South Avenue, Garden City, NY 11530.

Director-at-Large: Ellen Broidy, Coordinator of Library Education Services, 386 Main Library, University of California, Irvine, CA 92717; Barbara J. Wittkopf, Head of Reference Desk Services and BI, Middleton Library, Louisiana State University, Baton Rouge, LA 70803.

Director-at-Large: Karin E. Begg, Associate University Librarian for Systems and Technical Services, Boston College, 410 O'Neill Library, Chestnut Hill, MA 02167; Janice Bradley, P.O. Box 37100, Phoenix, AZ 85069; Ray E. Metz, Assistant 